\title{
Yannick FER, L'offensive évangélique. Voyage au cœur des réseaux militants de Jeunesse en Mission
} Genève, Labor et Fides, 2010, 183 p.

\section{Annie Benveniste}

\section{CpenEdition} Journals

Édition électronique

URL : http://journals.openedition.org/assr/22596

DOI : $10.4000 /$ assr.22596

ISSN : $1777-5825$

Éditeur

Éditions de l'EHESS

Édition imprimée

Date de publication : 31 décembre 2010

Pagination : 9-242

ISBN : 9782713223013

ISSN : 0335-5985

Référence électronique

Annie Benveniste, "Yannick FER, L'offensive évangélique. Voyage au cœur des réseaux militants de Jeunesse en Mission », Archives de sciences sociales des religions [En ligne], 152 | octobre-décembre 2010, document 152-50, mis en ligne le 12 mai 2011, consulté le 21 septembre 2020. URL : http:// journals.openedition.org/assr/22596; DOI : https://doi.org/10.4000/assr.22596

Ce document a été généré automatiquement le 21 septembre 2020.

(C) Archives de sciences sociales des religions 


\title{
Yannick FER, L'offensive
}

\section{évangélique. Voyage au cœur des réseaux militants de Jeunesse en Mission}

Genève, Labor et Fides, 2010, 183 p.

\author{
Annie Benveniste
}

\section{RÉFÉRENCE}

Yannick FER, L'offensive évangélique. Voyage au cœur des réseaux militants de Jeunesse en Mission, Genève, Labor et Fides, 2010, 183 p.

1 Yannick Fer nous emmène dans un voyage au cœur de l'organisation Youth With a Mission ou Jeunes en Mission, issue du mouvement évangélique, mais qui s'en démarque en proposant «un protestantisme hors les murs» et une nouvelle forme d'engagement pour les jeunes, conciliant transmission des valeurs et liberté de choix individuel. YWAM est créé en Californie, dans les années cinquante-soixante, par Loren Cunningham, héritier d'une tradition de prédicateurs protestants et des changements que connaît la société californienne animée par une sorte d'Utopia où tout reste à inventer. De tendance charismatique, YWAM, cherchant à construire une nouvelle sociabilité religieuse, se veut «non confessionnel», indépendant des dénominations religieuses.

2 Pour cela, YWAM met en place un programme de formation fondé sur les objectifs principaux de globalisation et de mobilité répondant à la définition d'une organisation modulaire, peu hiérarchisée, un réseau de réseaux, articulant autonomie individuelle et liens d'interdépendance. Il s'agit de lancer des jeunes enthousiastes, mais peu ou mal formés, sans véritable encadrement hiérarchique, sur des terrains réputés difficiles où ils noueront des relations amicales avec des populations dont ils ne maitrisent souvent 
pas la culture. La stratégie de l'organisation est ainsi définie par Cunningham: «...apporter la Bonne Nouvelle à chaque personne constitue en quelque sorte l'infanterie de Dieu. Évangéliser les nations pourrait être sa force de frappe aérienne. Intercéder pour les nations pourrait se comparer à des missiles intercontinentaux». Elle se caractérise donc par la délimitation de zones d'influence où concentrer la bataille missionnaire liant forme individualisée de l'action et globalisation du combat spirituel qui passe, lui, par la mise en réseaux de prières ciblées sur des lieux précis. Mais, pour atteindre la jeunesse, YWAM adapte les méthodes missionnaires aux goûts culturels des jeunes générations: arts, divertissements et sports.

3 Après les premiers chapitres décrivant les objectifs et les stratégies de l'organisation, Yannick Fer nous conduit dans plusieurs sites où elle s'est déployée et qui représentent divers contextes géographiques et sociaux. Chaque site est l'occasion pour l'auteur de retracer l'histoire de l'implantation du protestantisme missionnaire, de ses transformations et de ses prolongements réalisés par les divers «entrepreneurs religieux». L'enquête commence dans le Pacifique, une des premières terres d'expansion d'YWAM. En Nouvelle-Zélande, le mouvement charismatique s'affirme, dans les années soixante, comme une réponse aux changements culturels, dans les domaines de la liberté individuelle, de la sexualité et de la morale. Plus tard, au tournant du XxI ${ }^{e}$ siècle, YWAM négocie avec le mouvement Island Breeze, favorable aux revendications des autochtones maoris. Ce dernier revendique la reconnaissance de leurs valeurs culturelles au nom de la liberté individuelle contre la contrainte des Églises missionnaires, alors que pour YWAM les expressions culturelles des futurs convertis servent d'autant mieux la communication qu'elles deviennent une forme d'assignation identitaire.

4 Le credo d'Island Breeze - sortir de sa culture pour y revenir par un choix personnel, mais avec une réinterprétation critique menée au nom de la «rédemption» des cultures - le positionne au cœur des conflits de génération et des enjeux de la transmission culturelle en situation de migration qui fournit des outils d'analyse pour l'étude des autres sites. À Paris, dans un contexte français, réfractaire à la visibilité des mouvements religieux dans l'espace social, l'implantation de YWAM offre un cas d'école pour réfléchir «aux régimes de légitimité et d'institution en religion». JEM (Jeunesse en mission) installe son secrétariat à Belleville en 1985, puis investit une église réformée tout en prônant l'expansion d'un réseau international. Pendant que l'Église, qui se veut ouverte et populaire, connaît un nombre croissant d'observants, JEM a du mal à se redéployer, en dépassant l'institution et selon ses principes combinant la bonne volonté multiculturelle et l'engagement individuel.

5 Le voyage se conclut en terre chinoise où les missionnaires, comme YWAM, trouvent un certain écho dans un contexte de dispersion et de recomposition des ressources symboliques puisées à des traditions religieuses différentes dans la mesure où ils privilégient l'expérience individuelle plutôt qu'une stricte orthodoxie. Pour créer une adéquation entre mobilité sociale et expansion des réseaux évangéliques, le site internet de YWAM China affiche que le cadre du travail en Chine est basé sur le concept Business as Mission. Le but est de créer des entreprises à vocation missionnaire, qui, tout en permettant la présence évangélique dans des lieux difficilement accessibles, élargit sa sphère d'influence, génère des emplois et soutient l'économie locale.

6 Ce voyage permet de comprendre les multiples facettes du mouvement dont l'ancrage dans la jeunesse explique le dynamisme, dépassant les appartenances sociales et 
institutionnelles. Les descriptions fines et détaillées des contextes historiques et géopolitiques des différentes missions montrent la complexité des réseaux et de leurs réalisations. 